\title{
SINGLE ANASTOMOSIS GASTRIC BYPASS (ONE ANASTOMOSIS GASTRIC BYPASS OR MINI GASTRIC BYPASS): THE EXPERIENCE WITH BILLROTH II MUST BE CONSIDERED AND IS A CHALLENGE FOR THE NEXT YEARS
}

\author{
Anastomose única no bypass gástrico (bypass gástrico com uma anastomose ou mini bypass gástrico): A experiência com \\ Billroth II deve ser considerada e é um desafio para os próximos anos
}

Italo BRAGHETTO', Attila CSENDES

From the 'Department of Surgery, Faculty of Medicine, University of Chile, Hospital José Joaquin Aguirre, Santiago, Chile

HEADINGS - Single Anastomosis. Gastric bypass. Bile reflux.
ABSTRACT - Introduction: Single anastomosis gastric bypass (one anastomosis gastric bypass or mini-gastric bypass) has been presented as an option of surgical treatment for obese patients in order to reduce operation time and avoiding eventual postoperative complications after Roux-en-Y gastric bypass. The main late complication could be related to bile reflux. Aim: To report the experiences published after Billroth II anastomosis and its adverse effects regarding symptoms and damage on the gastric and esophageal mucosa. Method: For data recollection Medline, Pubmed, Scielo and Cochrane database were accessed, giving a total of 168 papers being chosen 57 of them. Results: According the reported results during open era surgery for peptic disease and more recent results for gastric cancer surgery, bile reflux and its consequences are more frequent after Billroth II operation compared to Roux-en-Y gastrojejunal anastomosis. Conclusion: These findings must be considered for the indication of bariatric surgery.

\section{Correspondence: \\ Italo Braghetto \\ Email: ibraghet@hcuch.cl \\ Financial source: none \\ Conflict of interest: none}

Received for publication: 16/02/2017 Accepted for publication: 08/06/2017

DESCRITORES - Anastomose única. Bypass gástrico. Refluxo biliar.
RESUMO - Introdução: Bypass com anastomose única ou mini-bypass gástrico foi apresentado como oopção de tratamento cirúrgico para pacientes obesos, a fim de reduzir o tempo da operação e evitar complicações pós-operatórias após bypass gástrico Y-de-Roux. A principal complicação tardia pode estar relacionada ao refluxo biliar. Objetivo: Relatar as experiências publicadas após a anastomose Billroth II e seus efeitos adversos em relação aos sintomas e danos sobre a mucosa gástrica e esofágica. Método: A coleta de dados foi baseada na busca nas bases Medline, Pubmed, Scielo e Cochrane. Um total de 168 artigos foram revisados, tendo sido escolhidos 57 deles. Resultados: De acordo com os resultados relatados durante a operação da era aberta para doença péptica e resultados mais recentes para o tratamento cirúrgico do câncer gástrico, o refluxo biliar e suas consequências são mais frequentes após o Billroth II em comparação com a anastomose gastrojejunal em Y-de-Roux. Conclusão: Esses achados devem ser considerados para a indicação de cirurgia bariátrica.

\section{INTRODUCTION}

$\mathrm{n}$ the last years single anastomosis gastric bypass (SAGB) (one anastomosis gastric bypass or mini-gastric bypass) has been presented as an option of

surgical treatment for obese patients in order to reduce operation time and avoiding eventual postoperative complications after Roux-en-Y gastric bypass $(\text { RYGBP) })^{4,33,37}$. Up to now the results with this procedure in terms of weight loss, BMI reduction, and improvement of co-morbidities are quite similar to the RYGBP and sleeve gastrectomy ${ }^{6,30,55}$. However, a potential risk of complications related to bile reflux is possible, even if modifications of the technique in order to prevent it have been introduced. It is not confirmed whether with these technical modifications we can completely avoid bile reflux. Only clinical results concerning to symptoms or endoscopic findings have been published. Late bile related complications and objective evaluations are missing in order to demonstrate that bile reflux and its consequences do not exist.

The objective of this article is to perform an analysis of the reported experiences with Billroth II (BII) anastomosis and its adverse effects regarding symptoms and objective damage on the gastric and esophageal mucosa in order to consider these problems in patients who will be submitted to SAGB and to promote more objective investigations. 
METHOD

The most relevant literature concerning the experience with BII anastomosis published during the era of peptic ulcer surgery and the more recent publications regarding the results after laparoscopic BII anastomosis after distal gastrectomy for gastric cancer (specially performed in Asian countries) were analysed. For data collection, Medline, Pubmed, Scielo and Cochrane were included. For search publications terms as "bile reflux after Billroth II" "bile reflux" "bile gastritis after gastrectomy" and "gastric stump cancer were used". A total of 168 papers was reviewed choosing 57 of them to be included for the analysis focused on the presence of symptoms, effects on the esophageal and gastric mucosa and objective evaluation of bile reflux comparing the results published after BII anastomosis vs. RYGBP reconstruction.

\section{RESULTS}

For restoration of gastrointestinal tract after partial distal resection of thestomach therearethreeoptions: gastroduodenostomy (Billroth I), gastrojejunostomy with BII anastomosis or with Roux-en-Y anastomosis. After Billroth I or II there are three potential risks: biliary gastritis, bile esophagitis or gastric cancer which have a close relationship with bile reflux into the gastric stump. Regarding to the presence of bile reflux into the gastric stump and distal esophagus there is enough evidence reported in previous publications during the period of peptic ulcer surgery and also more recent literature after laparoscopic distal gastrectomy for gastric cancer.

Bile reflux has been evaluated with scintigraphic assessment - Bilitec2000 -, or bile salt concentration measurement. Figure 1 shows the typical scintigraphic image demonstrating reflux after Bll anastomosis and no reflux after Roux-en-Y gastrojejunostomy (RYGJ) anastomosis. Bile reflux has demonstrated to be higher after Bll reconstruction compared with RYGJ. High concentrations of bile acid seem to be associated with an elevated risk of intestinal metaplasia. It has been demonstrated a very strict relationship between bile reflux and appearance of symptoms secondary to different grade of gastritis 3,27,2,9.

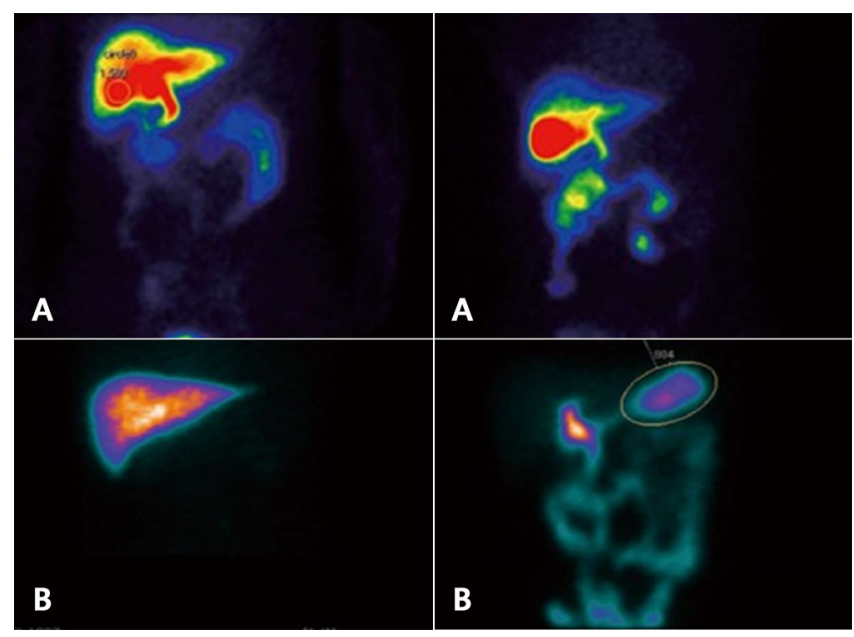

FIGURE 1 - Examination of duodenogastric reflux by ${ }^{99 m}$ Tc-ethyl hepatic iminodiacetic acid test: $A$ ) negative: $B$ ) positive

After gastric surgery due to peptic ulcer disease, 25\% of patients have postoperative symptoms, and $5 \%$ of them present severe symptoms at the early or middle term followup due to esophagitis and Barrett's or biliary gastritis due to bile reflux. The most frequent symptoms are heartburn, pain, abdominal fullness, early satiety, diarrhea or dumping, the last due to fast gastric emptying or small remnant syndrome.
The other important late complication is the development of stump gastric cancer mainly associated with bile reflux ${ }^{5}$ $, 38,18,45,29,31,25,47,20,57$.

Since the 80 's decade, there is a hugh evidence concerning the high rate of endoscopic and histological damage at the esophageal or gastric mucosa secondary to bile reflux. $D^{\prime}$ Amato ${ }^{12}$ published endoscopic and histological reflux esophagitis after BII anastomosis in $47 \%$ of patients and only $13 \%$ after RYGJ anastomosis and De Vita ${ }^{21}$ demonstrated endoscopic gastritis in $88.8 \%$ and histological atrophic gastritis in $94.4 \%$ after BII and only $29.4 \%$ and $58 \%$ of superficial gastritis after Roux-en-Y anastomosis, respectively $(p<0.001)$. Csendes et al. ${ }^{11}$, in a prospective randomized study demonstrated symptoms of gastroesophageal reflux in $33.3 \%$ after Bll operation compared to $3.2 \%$ after RYGJ $(p<0.002)$. In adition, they reported endoscopic esophagitis with intestinal metaplasia at the distal esophagus in $20 \%$ of patients after BII, while after RYGJ these findings were present in $3.2 \%(p<0.001)$. In the same paper, bile reflux to gastric stump with chronic athrophic gastritis appeared in $40 \%$ of cases after BII against $10 \%$ after RYGJ ${ }^{11}$.

More recently, Asian authors $38,18,45,29,31,25,47,20,57$ have published similar results evaluating presence of bile reflux, reflux esophagitis and histologic gastritis after distal gastrectomy for gastric cancer comparing BII vs. RYGJ. They confirmed that erosive esophagitis grade A or B is significantly more frequent after BII anastomosis than after RYGJ (53.6\% vs. $23 \%$ respectively, $\mathrm{p}<0.017)$ and bile reflux and gastritis was present in almost $85 \%$ of patients with BII operation. A metanalysis of Zong et $\mathrm{al}^{57}$ comparing Billroth I vs. BII vs. Roux-en-Y following distal gastrectomy based on 15 studies, concluded that Billroth I or II reconstruction showed significantly more reflux symptoms, increased gastritis and esophagitis, compared to patients with Roux-en-Y gastrojejunostomy, and quality of life was significantly improved in patients with Rouxen-Y reconstruction. This meta-analysis highlights clinical advantages of the last after distal gastrectomy.

In Table 1, 2 and 3 comparative results obtained from the literature reviewed in terms of postoperative symptoms of bile reflux and objective endoscopic and histological findings after BII vs. RYGJ are presented. All these studies concluded that BII reconstruction is associated with increased bile reflux in near to $70-80 \%$ of patients promoting symptoms, erosive esophagitis, Barrett's and gastritis ${ }^{51,1,34,17}$.

TABLE 1 - Symptoms related to bile reflux after BII vs. Rouxen-Y gastrojejunostomy (\%)

\begin{tabular}{l|c|c|} 
& $\begin{array}{c}\text { Billroth II - mean } \\
\text { (variation) }\end{array}$ & $\begin{array}{c}\text { Y-de-Roux - mean } \\
\text { (variation) }\end{array}$ \\
\hline Asymptomatic & $45,5(36-83,3)$ & $80,6(74,6-96,8)$ \\
\hline GERD Symptoms & $15,5(10,9-24,4)$ & $7,5(3,2-17,2)$ \\
\hline Gastrointestinal symptoms & $12,9(5,8-23,1)$ & $8,5(0-25)$ \\
\hline
\end{tabular}

TABLE 2 - Endoscopic findings related to bile reflux after Billroth II and Roux-en-Y gastrojejunostomy (\%)

\begin{tabular}{|c|c|c|}
\hline & $\begin{array}{l}\text { Billroth II - mean } \\
\text { (variation) }\end{array}$ & $\begin{array}{c}\text { Y-de-Roux - mean } \\
\text { (variation) }\end{array}$ \\
\hline \multicolumn{3}{|l|}{ Esophagus } \\
\hline Normal & $56,2(46,270,9)$ & $82,6(75-90,3)$ \\
\hline $\begin{array}{r}\text { Erosive } \\
\text { esophagitis }\end{array}$ & $30,6(2,4-53,9)$ & $9,2(0-25)$ \\
\hline Barrett & 2,5 & 0 \\
\hline Carcinoma & 3,0 & 0 \\
\hline \multicolumn{3}{|l|}{ Stomach } \\
\hline Normal & $17,9(4,1-34,2)$ & $78,5(35-100)$ \\
\hline Erosive esophagitis & $87,8(82,3-96,1)$ & $37,3\left(17,4-65,1^{\star}\right)$ \\
\hline Presence of bile & $77,9(66-88)$ & $16,9\left(3,7-42^{*}\right)$ \\
\hline
\end{tabular}


TABLE 3 - Histologic findings of distal esophagus and gastric stump after Billroth II or Roux-en-Y gastrojejunostomy in patients submitted to distal gastrectomy (\%)

\begin{tabular}{|c|c|c|}
\hline & $\begin{array}{l}\text { Billroth II - mean } \\
\text { (variation) }\end{array}$ & $\begin{array}{l}\text { Y-de-Roux - mean } \\
\text { (variation) }\end{array}$ \\
\hline \multicolumn{3}{|l|}{ Distal esophagus } \\
\hline Esophagitis & $19,3\left(2,4-45,4^{\star}\right)$ & $15,9\left(0-45,2^{\star}\right)$ \\
\hline Intestinal metaplasia & $25,6(21,2-30)$ & $1,6 \quad(0-3,2)$ \\
\hline Carcinoma & 3,1 & 0 \\
\hline \multicolumn{3}{|l|}{ Gastric stump } \\
\hline Normal mucosa & 15,1 & 16 \\
\hline Gastritis & $71,8\left(39,4-94,4^{*}\right)$ & $14,7\left(1,8-58^{\star \star}\right)$ \\
\hline Intestinal metaplasia & 6,1 & 0 \\
\hline
\end{tabular}

The second important complication is regarding to the risk of developing gastric cancer late after surgery. There is vast information about the pathogenesis and incidence of gastric stump carcinoma. First at all, the pathophysiological mechanisms involved have been studied by several authors. Enterogastric bile reflux induces damage of gastric mucosa, hypochloridia favouring the bacterial colonization and presence of secondary bile acid, all together proved factors for carcinogenesis, developing chronic athrophic gastritis, intestinal metaplasia, inducing adenocystic changes, abnormal cell kinetics; the final result is the appearance of gastric stump carcinoma. In gastric stump, the Helicobacter pylori infection rate range 17-68\% $\%^{39,10,49,46,43,35,15,40,56,23}$ (Figure 2).

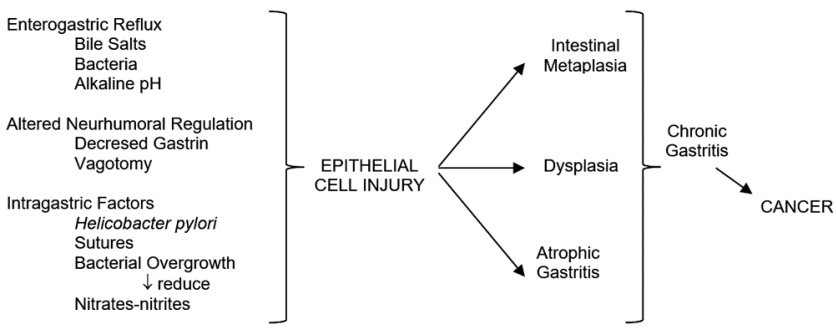

FIGURE 2 - Mechanisms involved in the development of stump gastric cancer after distal gastrectomy

Definitively, high levels of duodenogastric reflux observed after Bll gastric resection are associated with high bile reflux with polyamine concentration in the gastric mucosa, associated with bacterial microflora, presence of mainly free secondary and primary bile acids which may contribute to the high incidence of cancer in the gastric remnant observed after BII operations. All these facts can be considered as important causal factors of the increased risk of gastric stump cancer after this operation $39,10,49,46,43,35,15,40,56,23$.

Currently due to the improvement of medical treatment with PPI's inhibitors, gastrectomy for benign disease has decreased over the last two decades. Still, this type of gastric stump carcinoma has not decreased due to the long latency period required for carcinogenesis after initial surgery. Hokosawa and Morgagni ${ }^{19,41}$ described the acumulative risk of developing gastric stump cancer after curative distal gastrectomy for early gastric cancer which was $2.5 \%$ at 5 -years, 2.5 to $6.1 \%$ at 10 years, $3.2 \%$ at 15 -years and $4 \%$ at 20 -years follow-up $19,41,44,50$ $, 13,26,52,36,54,28,53,21,48$. The incidence range from $1-8 \%$ of patients submitted to distal gastric resection with BII anastomosis. The incidence is 4-7 times more frequent compared to the general population and increases $28 \%$ each 5 -year follow up. The interval time for the appearance ranges from 4-57 years. The risk decreases depending the age of the initial operation. Patients over 50 years have low risk of developing stump gastric carcinoma, but bariatric patients very often have less than 30 years when are submitted to surgery, and therefore the risk to have cancer at 50 year age is considerable. Table 4 shows the reported prevalence of stump gastric carcinoma after distal gastrectomy exclusively for benign causes $13,26,52,36,54,28,53,21$.

TABLE 4 - Summary of stump gastric carcinoma after distal gastrectomy for benign disease.

\begin{tabular}{|l|c|c|}
\hline \multicolumn{1}{|c|}{ Authors } & $($ ref) & Intake interval (years) \\
\hline Di Leo & $(42)$ & $34,6(8-57)$ \\
\hline Komatsu & $(43)$ & $30,0(4-51)$ \\
\hline Tanigawa & $(45)$ & $25,8(10-40)$ \\
\hline Lundergath & $(46)$ & $20,0(5-30)$ \\
\hline Tersmette & $(47)$ & $17,5(15-20)$ \\
\hline Lagergren & $(48)$ & $20,5(15-30)$ \\
\hline Tassi & $(50)$ & $30,0(6-42)$ \\
\hline
\end{tabular}

Recent publications have reported gastric cancer after non-resectional gastric bypass, situation in which the same pathophysiological mechanism with bile reflux and presence of bacterial colonization can occurs. Orlando et al ${ }^{44}$ published a review of the literature about the cases of gastric cancer arising after any bariatric procedure. Globally, 17 case reports describing 18 patients were retrieved, including the case study by the authors. The diagnosis of tumor was at a mean of 8.6 years after bariatric surgery, 9.3 years after RYGB, and 8.1 years after restrictive procedures. The adenocarcinoma represented most cases localized in the gastric stump (83\%). After a restrictive procedure, the cancer was localized in the pouch in $62.5 \%$ of cases, in the pylorus in $25 \%$, and in lesser curvature in $12.5 \%$. Scozzari et al ${ }^{50}$ in other review including 28 articles described 33 patients retrieved. Neoplasms were diagnosed at a mean of 8.5 years after bariatric surgery (range two months to 29 years). Node involvement was reported in almost $60 \%$ of cases, and distal metastases in $15 \%$. Reported mortality rate was $48.1 \%$. To date, it is not possible to quantify the incidence of esophagogastric cancer after bariatric surgery because of the paucity of reported data. However, being the main concern the delay in diagnosis, it is of critical importance to evaluate carefully any new upper digestive tract symptom appearing after bariatric surgery. Other important point to take in account is the fact that most of the available data are coming from areas with low rate of gastric cancer compared to Asian or Latin-American countries where gastric cancer has a high incidence.

The study of Inoue et $\mathrm{al}^{21}$ shows that RYGB reduces the risk of gastric cancer in an experimental model of dietary-induced carcinogenesis due to lower bile reflux, and a lower bacteria concentration in the gastric content. This data suggest that RYGB may be a safe option for the treatment of morbid obesity even in areas with high gastric cancer incidence.

\section{CONCLUSION}

In front to these previous experiences and pathophysiologic considerations, SAGB appears as a surgical technique that rapes important surgical concepts. Actually, different authors propose some modifications of classical Bll procedure by suturing the jejunum very high along the vertical stapled line in order to avoid bile reflux. Others propose to perform a long and thin gastric tube and they believe that in this way it is possible to create a low pressure system in order to favour the gastric emptying 4,33,37,6,30,55. All these mechanisms are conducted to avoid bile reflux. However, gastric physiology is not only a mechanical event ${ }^{4,33}$ $, 37,6,30,55,48,32,42,8,7$. Up to now in the available literature concerning to $S A G B$, only clinical studies have been reported, specially focused in the weight loss and improvement of comorbidities. Criticism and prejudice against this procedure was raised by surgeons who preferred a more complex procedure, such as laparoscopic RYGB. Increasing data indicate that the procedure is an effective and durable bariatric procedure. SAGB has lower operation risks compared to RYGB. The weight loss is better 
after SAGB because of a greater mal-absorptive component than RYGB, but SAGB has a higher incidence of micronutrient deficiencies. Randomized controlled trial and long-term data demonstrated that SAGB can be regarded as a simpler and safer alternative to RYGB. The authors have proposes to renamed "single-anastomosis gastric bypass (SAGB)" because the key feature of SAGB is the "single anastomosis" compared with the two anastomosis of RYGB ${ }^{54,28,53,2148,32,42}$. This technique is not exempt of surgical complications, such as Petersen's internal hernia or afferent loop apart of bile reflux ${ }^{54-57}$. Few papers have been dedicated to objective evaluation of bile reflux. Johnson et al ${ }^{22}$ reported bile reflux in almost $60 \%$ of patients similar to the papers published during the era of peptic ulcer surgery $3,2,22$. We have no information about the endoscopic and histologic damage of esophageal and gastric mucosa, Bilitec 2000, bile salt concentration and type of bile salts at the gastric stump, or scintigraphic assessment for bile reflux now in patients submitted to SAGB. It is necessary to develop these objective studies in order to exclude or confirm the presence of distal esophagus or gastric stump damage. This is the challenge for surgeons interested in demonstrated the advantages of SAGBP during the next years in order to convince that this technique is an option for bariatic surgery without the risk of the complications analyzed. After the results of these studies we can delucidate the controversy.

\section{REFERENCES}

1. Abe H, Murakami K, Satoh $S$, Sato R, Kodama M, Arita T, Fujioka T. Influence of bile reflux and Helicobacter pylori infection on gastritis in the remnant gastric mucosa after distal gastrectomy. J Gastroenterol. 2005; 40: 563-9.

2. Braghettol.Indicacionesyresultadosdelempleodelagastroyeyunoanastomosis en Y de Roux en patología gástrica benigna. Rev Chil Cir. 1993; 45: 48-52

3. Braghetto I, Yarmuch J, Csendes A. Alkaline reflux gastritis. Rev Med Chile. 1983;111:1169-76.

4. Bruzzi M, Rau C, Voron T, Guenzi M, Berger A, Chevallier JM. Single anastomosis or mini-gastric bypass: long-term results and quality of life after a 5-year follow-up. Surg Obes Relat Dis. 2015; 11: 321-6.

5. Capretti PG, Hüscher C. Follow-up of patients with Roux-technique gastric resection. Comparison of Billroth land Billroth Il gastric resections. Minerva Chir. 1991; 46: 671-7.

6. CarbajoMA,JiménezJM,CastroMJ,Ortiz-SolórzanoJ,ArangoA.Outcomes in weight loss, fasting blood glucose and glycosylated hemoglobin in a sample of 415 obese patients, included in the database of the European accreditation council for excellence centers for bariatric surgery with laparoscopiconeanastomosisgastricbypass. NutrHosp.2014;30:1032-8.

7. Carbajo MA, Fong-Hirales A, Luque-de-León E, Molina-Lopez JF Ortiz-de-Solórzano J.Weight loss and improvement of lipid profiles in morbidly obese patients after laparoscopic one-anastomosis gastric bypass: 2-year follow-up. Surg Endosc. 2016 Jun 17. [Epub ahead of print] PMID:27317038

8. Carbajo MA, Luque-de-León E, Jiménez JM, Ortiz-de-Solórzano J, PérezMiranda M, Castro-Alija MJ. Laparoscopic One-Anastomosis Gastric Bypass: Technique, Results, and Long-Term Follow-Up in 1200 Patients. Obes Surg. 2016 Oct 25 [Epub ahead of print] PMID: 27783366

9. Chen TF, Yadav PK, Wu RJ, Yu WH, Liu CQ Lin H, Liu ZJ. Comparative evaluation of intragastric bile acids and hepatobiliary scintigraphy in the diagnosisof duodenogastricreflux. World J Gastroenterol.2013;19:2187-96.

10. Correa P. Clinical implications of recent developments in gastric cancer pathology and epidemiology. Semin Oncol. 1985;12:2-10.

11. Csendes A, Burgos AM, Smok G, Burdiles P, Braghetto I, Diaz JC. Latest results (12-21years) of a prospective randomized study comparing Billroth II and Roux em Y anastomosis after a partial gastrectomy plus vagotomy in patients with duodenal ulcers. Ann Surg 2009:249:89-194

12. D'Amato A., Montesani C, Cristaldi M, Giovannini C, Peonio A, Santella S, Ventroni G, Ronga G, Ribotta G. Restorarion of digestive continuity after subtotal gastrectomy: comparison of the methods of Billroth I, II and Roux-en-Y. Randomized prospective study Ann Ital Chir 1999:70:51-66

13. Di Leo A, Pedrazzani C, Bencivenga M, Coniglio A, Rosa F, Morgani $P$ MarrelliD, Marchet A, Cozzaglio L, Giscopuzzi S, Tiberio GA, Doglietto GB, Vittimberga G, Roviello F, Ricci F. Gastric stump cancer after distal gastrectomy for benign disease: clinicopathologic features and surgical outcomes. AnnSurg Oncol 2014;21:2594-2600

14. Di Vita G, Costa R, Siragusa G, Asaro M, Aragona S, Scafidi A, Di Pace G. Gastric emptying after duodeno gastric resection. Minerva Chir. 1991:15;46:169-73
15. Domellöf L, Reddy BS, Weisburger JH. Microflora and deconjugation of bile acids in alkaline reflux after partial gastrectomy. Am J Surg. 1980:140291-5.

16. Facchiano $E$, lannelli $A$. Lucchese $M$ Internal hernia after mini-gastric bypass: Myth or reality? J Visc Surg. 2016;153:231-2.

17. Fukuhara K, Osugi H, Takada N, Takemura M, Higashino M, Kinoshita $\mathrm{H}$. Reconstructive procedure after distal gastrectomy for gastric cancer that best prevents duodenogastroesophageal reflux. World J Surg. 2002;26:1452-7.

18. Fukuhara K, Osugi H, Takada N, Takemura M, Lee S, Taguchi S, Kaneko M, Tanaka Y, Fujiwara Y, Nishizawa S, Kinoshita H. Correlation between duodenogastric reflux and remnant gastritis after distal gastrectomy. Hepatogastroenterology. 2004;51:1241-4.

19. Hososkawa O, Kaisaki Y, watanabe K, Hatori M, Duoden K, Hayashi H, Maeda S. Endoscopic surveillance for gastric remnant cancer after early cancer surgery. Endoscopy 2002;34:469-73

20. In Choi C, Baek DH, Lee SH, Hwang SH, Kim DH, Kim KH, Jeon TY, Kim DH. Comparison Between Billroth-II with Braun and Roux-en-Y Reconstruction After Laparoscopic Distal Gastrectomy.J Gastrointest Surg. 2016;20:1083-90

21. Inoue $H$, Rubino F, Shimada $Y$, Lindner $V$, Inoue $M$, Riegel $P$, Marescaux J. Risk of gastric cancer after Roux-en-Y gastric bypass. Arch Surg. 2007 ;142:947-53

22. Johnson WH, Fernanadez AZ, Farrell TM, Macdonald KG, Grant JP, McMahon RL, Pryor AD, Wolfe LG, DeMaria EJ. Surgical revision of loop ("mini") gastric bypass procedure: multicenter review of complications and conversions to Roux-en-Y gastric bypass. Surg Obes Relat Dis. 2007:3:37-41.

23. Kamonishi M, Shimizu N, Shiomoyama S, yamaguchi,H,Ogawa T, Sakai $\mathrm{S}$, Kuramoto S, OOhra T. Etiology of gastric remnant cancer with special reference to the effects of denervation of the gastric mucosa. Cancer 1995; 75:1490-96

24. Kassir R, Blanc P, Lointier P, Breton C, Debs T, Tiffet O Laparoscopic Revision of an Omega Loop Gastric Bypass to Treat Afferent Loop Syndrome Obes Surg. 2015;25:1976-8.

25. Kim Ch H, Song Y, Park Ch H. A comparison of outcomes of three reconstruction methods after laparoscopic distal gastrectomy. J. Gastric cancer 2015;15:46-52

26. Komatsu S, Ichikawa D, Okamoto K, Ikoma D, Tsujiura $M$, Nishimura Y, Murayama Y, Shiozaki A, Ikoma H, Kuriu Y, Nakanishi M, Fujiwara $\mathrm{H}$, Ochiai T, Kokuba Y, Otsuji E Progression of remnant gastric cancer is associated with duration of follow-up following distal gastrectomy. World J Gastroenterol. 2012;18:2832-6

27. Kondo K. Duodenogastric reflux and gastric stump carcinoma. Review Gastric cancer 2002; 5:16-22

28. Lagergreen J, Lindam A, Mason RM. Gastricstumo cancer after distal gastrectmy for benign ulcer in a population based study. Int J. cancer 2012;131:E1048-E1052

29. Lee MS, Ahn SH, Lee JH, Park DJ, Lee HJ, Kim HH, Yang HK, Kim N, Lee WW. What is the best reconstruction method after distal gastrectomy for gastric cancer? Surg Endosc. 2012;26:1539-47.

30. LeeWJ, Chong K, Lin YH,WeiJH,ChenSCLaparoscopicsleevegastrectomy versus single anastomosis (mini-) gastric bypass for the treatment of type 2 diabetes mellitus: 5 -year results of a randomized trial and study of incretin effect. Obes Surg. 2014;24:1552-62

31. Lee WJ, Lee YC, Ser KH, Chen SC, Chen JC, Su YH. Revisional surgery for laparoscopic minigastric bypass.Surg Obes Relat Dis. 2011;7:486-91

32. Lee WJ, Lin YH Single-anastomosis gastric bypass (SAGB): appraisal of clinical evidence. Obes Surg. 2014;24:1749-56.

33. LeeWJ, Ser KH, LeeYC, Tsou JJ, Chen SC, Chen JC. Laparoscopic Roux-en-Y vs. mini-gastric bypass for the treatment of morbid obesity: a 10-year experience. Obes Surg. 2012;22:1827-34

34. LeeY, Tokunaga A, Tajiri T, Masuda G, OkudaT, Fujita I, Kiyama T, Yoshiyuki T, Kato S, Matsukura N, Yamada N. Inflammation of the gastric remnant after gastrectomy: mucosal erythema is associated with bile reflux and inflammatory cellular infiltration is associated with Helicobacter pylori infection.J Gastroenterol. 2004;39:520-6.

35. Lorusso D, Linsalata M, Pezzolla F, Berloco P, Osella AR, Guerra V, Di Leo A, Demma I. Duodenogastric reflux and gastric mucosal polyamines in the non-operated stomach and in the gastric remnant after Billroth II gastric resection. A role in gastric carcinogenesis? Anticancer Res. 2000;20(3B):2197-201.

36. Lundegärdth G, Adami HO, Helmick C, Zack M, Mairik O, Stomach cancer after partial gastrectomy for beningn disease. N Engl J. Med 1988; 319:1540-47

37. Mahawar KK, Kumar P, Carr WR, Jennings N, Schroeder N, Balupuri S, Small PK. Current status of mini-gastric bypass. J Minim Access Surg. 2016:12:305-10.

38. Matsuhisa T, Arakawa T, Watanabe T, Tokutomi T, Sakurai K, Okamura S, Chono S, Kamada T, Sugiyama A, Fujimura Y, Matsuzawa K, Ito M, Yasuda $\mathrm{M}, \mathrm{Ota} \mathrm{H}$, Haruma K. Relation between bile acid reflux into the stomach and the risk of atrophic gastritis and intestinal metaplasia: a multicenter study of 2283 cases. Dig Endosc. 2013;25:519-25 
39. MeyerF, BenedixF, GalippB, LippertH, MeyerL.Gastricstumpcarcinoma-a surgical and oncological challenge. Z Gastroenterol. 2011;49:1270-5

40. MiwaK,HattoriT,Miyazakil.Duodenogastricrefluxandforegutcarcinogenesis. Cancer. 1995;75:1426-32

41. Morgagni $P$, Gardini A, Marrelli D, Vittiberga G, Marchet A, de Manzoni G, Di cosmo MA, Rossi GM, Garcea D, RovielloF. Gastric stump carcinom after distal subtotal gastrectomy for early gastric cancer: experience of 541 patients with long term follow-up. Am J. Surg. 2015;209:1063-68

42. Musella M, Susa A, Greco F, De Luca M, Manno E, Di Stefano C, Milone M, Bonfanti R, Segato G, Antonino A, Piazza L The laparoscopic minigastric bypass: the Italian experience: outcomes from 974 consecutive cases in a multicenter review. Surg Endosc. $2014 ; 28: 156-63$.

43. Ohira M, Toyokawa T, Sakurai K, Kubo N, Tanaka H, Muguruma K, Yashiro M, Onoda N, Hirakawa K. Current status in remnant gastric cancer after distal gastrectomy. World J Gastroenterol. 2016;22:2424-33.

44. Orlando G, Pilone V, Vitiello A, Gervasi R, Lerose MA, Silecchia G, Puzziello A. Gastric cancer following bariatric surgery: a reviewSurg Laparosc Endosc Percutan Tech. 2014;24:400-5

45. Osugi H, FukuharaK, Takada N, TakemuraM, KinoshitaHH. Reconstructive procedure after distal gastrectomy to prevent remnant gastritis. Hepatogastroenterology. $2004 ; 51: 1215-8$.

46. Păduraru DN, Nica A, Ion D, Handaric M, Andronic O. Consideration on risk factors correlated to thr occurrence of gastric stump cancer. J Med Life. 2016;9: 130-136

47. Park JY, Kim YJ. Uncut Roux-en-Y Reconstruction after Laparoscopic Distal Gastrectomy Can Be a Favorable Method in Terms of Gastritis, Bile Reflux, and Gastric Residue. Gastric Cancer 2014:14:229-237

48. Rutledge R, Walsh TR.Continued excellent results with the mini-gastric bypass: six-year study in 2,410 patients.Obes Surg. 2005;15:1304-8

49. Safatle Ribeiro A, Ribeiro U Jr, Reynolds JC. Gastric stump cancer: whats is the risk? Dig Dis 1998;16:159-168
50. Scozzari G, Trapani R, Toppino M, Morino M Esophagogastric cancer after bariatric surgery: systematic review of the literature.Surg Obes Relat Dis. 2013:9:133-42.

51. Shim JH, Oh SI, Yoo HM, Jeon HM, Park CH, Song KY Roux-en-Y gastrojejunostomyaftertotallylaparoscopicdistalgastrectomy:comparison with Billorth II reconstruction.Surg Laparosc Endosc Percutan Tech. 2014;24448-51.

52. Tanigawa N, Nomura E, Lee SW, Kaminishi M, Sugiyama M, Aiku T, Kitajima M. Current state of gastric stumpcarcinoma in Japan: based on the results of nationwide survey. World J, Surg 2010;34:1540-47

53. Tassi A, Goracci GL, Volpi G, Cirocchi R. Primary cancer of the gastric stump. Apropos of 8 cases. Ann Chir. 1995;49:155-9.

54. Tersmette AC, Offerhaus GJ, Tersmette KW, Giardello FM, Mooe GW Tytgat GN, Vanderbrouke JP. Metaanlysis of the risk of gastric cancer after remote partial gastrectomy for benign conditions Cancer res 1990;50:6486-89

55. Victorzon M. Single-anastomosis gastric bypass: better, faster, and safer? Scand J Surg. 2015;104:48-53.

56. Zlatić A, Stojanovic M, Mihailovi D, Dinic BR, Protic M, Veljocovic R. The role of duodeno gastric reflux in formation of precarcinogenic gastric lesions: an eperimental study. Med Pregl. 2013;66:285-91

57. Zong L, Chen P.Billroth I vs. Billroth II vs. Roux-en-Y following distal gastrectomy: ameta-analysisbasedon 15 studies. Hepatogastroenterology 2011:58:1413-24 